\title{
Karakteristik Struktur Dan Termal Komposit Aspal Karbosil Silika Sekam Padi
}

\author{
Devi Yulianti*, Simon Sembiring, dan Junaidi \\ (1) Jurusan Fisika, Universitas Lampung,Bandar Lampung, Indonesia, 35141 \\ Email :(a*) deviyuli.dv@gmail.com, ${ }^{(b)}$ simon.sembiring@fmipa.unila.ac.id, \\ (c)junaidi.1982@fmipa.unila.ac.id
}

Diterima (24 November 2021), Direvisi (12 Desember 2021)

\begin{abstract}
Synthesis and characterization of asphalt have been modified with carbosil and silica. This research was conducted to determine the microstructure and structure of the asphalt carbosil silica composite with a weight composition ratio of 50:50:0; 42.5:42.5:15; 40:40:20; 37.5:37.5:25; 35:35:30; 32.5:32.5:35. Silica is obtained from rice husk using the sol gel method and carbosil was obtained by the pyrolysis method. The results of XRD analysis obtained that the phase formed from each composition variation was an amorphous phase. The DTA/TGA analysis shows that there is a change in energy due to the addition of heat, which is indicated by the presence of mass shrinkage in the sample. Variations in the composition of the sample indicate a decrease in the value of the compressive strength, and the swelling thickness.
\end{abstract}

Keywords: asphalt, carbosil, silica, XRD, and DTA/TGA

Abstrak. Telah dilakukan sintesis dan karakterisasi aspal yang dimodifikasi dengan karbosil dan silika. Penelitian ini dilakukan untuk mengetahui mikrosuktur dan struktur komposit aspal karbosil silika dengan perbandingan komposisi berat yaitu 50:50:0; 42,5:42,5:15; 40:40:20; 37,5:37,5:25; 35:35:30; 32,5:32,5:35. Silika diperoleh dengan menggunakan metode alkalis dan karbosil diperoleh dengan metode pirolisis. Hasil analisis XRD diperoleh fasa yang terbentuk dari setiap variasi komposisi adalah fasa amorf. Analisis DTA/TGA menunjukkan terjadinya perubahan energi akibat penambahan panas dengan ditandai adanya penyusutan massa pada sampel. Variasi komposisi pada sampel menunjukkan terjadinya penurunan nilai pada kuat tekan dan perubahan ketebalan.

Kata kunci: aspal, karbosil, silika, XRD, dan DTA/TGA.

\section{PENDAHULUAN}

Aspal merupakan bahan pengikat berwarna coklat tua hingga hitam yang dihasilkan dari minyak mentah melalui proses destilasi minyak bumi [1]. Komposisi aspal terdiri dari karbon (82$88 \%)$, hidrogen $(8-11 \%)$, sulfur $(0-6 \%)$, oksigen (0-1,5\%), dan nitrogen (0-1\%) [2]. Aspal akan menjadi cair pada saat suhu tinggi dan saat suhu rendah aspal akan menjadi keras dan lengket. Sifat ini mengakibatkan aspal rentan terhadap suhu, sehingga aspal mudah mengalami keretakan dan kerusakan. Oleh karena itu, perlu dilakukan penambahan bahan aditif pada campuran aspal untuk meningkatkan kinerja aspal. Saat ini, beberapa bahan telah digunakan untuk memperbaharui karakteristik aspal dalam menahan efek suhu dan efek beban aspal dengan penambahan bahan silika [3].

Beberapa bahan nabati yang dapat digunakan sebagai sumber silika antara lain tongkol jagung, alang-alang, rumput gajah dan sekam padi [4]. Silika sekam padi dapat diperoleh dengan metode alkalis. Penelitian mengenai ekstraksi silika sekam padi dengan metode alkalis memperoleh silika pada tingkat kemurnian 94,66\% [5].

Silika memiliki kerapatan $2,608 \mathrm{~g} / \mathrm{cm}^{3}$ dan kestabilan termal yang tinggi hingga suhu $1414{ }^{\circ} \mathrm{C}$, mudah menyerap air, adsorpsi yang kuat, homogenitas yang 
tinggi, daya serap air yang tinggi dan porositas yang tinggi [6]. Silika sekam padi berpotensi sebagai campuran pada aspal dengan memanfaatkannya sebagai bahan pengisi [3].

Selain silika, bahan tambah lain yang dapat digunakan pada komposit aspal yaitu karbosil. Karbosil adalah material yang tersusun dari silika dan karbon. Karbosil dapat diperoleh dengan bahan baku silika dan metilen klorida [7] dan metode pirolisis [8]. Karbosil memiliki kelebihan terhadap suhu tinggi hingga $1400{ }^{\circ} \mathrm{C}$, memiliki luas permukaan sebesar $114,061 \mathrm{~m}^{2} / \mathrm{g}$, dan mempunyai ukuran pori 2-5 $\mu \mathrm{m}$ [9]. Berdasarkan karakteristik tersebut, karbosil berpotensi untuk sebagai bahan pengisi pada campuran aspal.

Penelitian terkait komposit aspal telah dilakukan dengan menambahkan silika menunjukkan hasil bahwa komposit aspal yang ditambahkan silika dapat meningkatkan kekuatan sobek dan resistensi terhadap suhu tinggi [10], meningkatkan titik lembek, viskositas, kuat tarik, tahan terhadap keretakan dan kelembaban [3].

Berdasarkan uraian di atas, peneliti tertarik untuk melakukan pencampuran aspal dengan karbosil dan silika untuk mengetahui karakteristik struktur dan termal aspal silika karbosil komposit. Hasil dari penelitian ini diharapkan dapat diketahui variasi modifikasi aspal yang lebih baik dengan mengetahui sifat fisis, sifat mekanik, struktur fasa dan sifat termal komposit aspal karbosil silika.

\section{METODE PENELITIAN}

\section{Alat dan Bahan}

Alat-alat yang digunakan dalam penelitian ini adalah beaker glass, neraca digital, mortar dan pestle, hot plate, cetakan pellet, $\mathrm{pH}$ indicator, magnetic stirrer, alat pirolisis dan oven. Bahan-bahan yang digunakan dalam penelitian ini adalah sekam padi, $\mathrm{NaOH} 1,5 \%, \mathrm{HNO}_{3} 10 \%$, akuades dan aspal sebagai bahan pengikat.

\section{Metode Penelitian}

Sekam padi yang telah bersih ditimbang sebanyak 50 gram, kemudian dimasukkan ke dalam beaker glass. Selanjutnya ditambahkan larutan $\mathrm{NaOH} \quad 1,5 \%$ dan dipanaskan selama 30 menit kemudian ditutup dengan aluminium foil dan didiamkan selama 24 jam. Setelah itu filtrat sol silika disaring dan kemudian ditetesi larutan $\mathrm{HNO}_{3} 10 \%$ hingga $\mathrm{pH}$ sol mencapai 7 dan terbentuk gel. Kemudian gel dikalsinasi dengan suhu $100{ }^{\circ} \mathrm{C}$ selama 4 jam hingga diperoleh silika padatan. Karbosil diperoleh dengan proses pembakaran pada suhu $450{ }^{\circ} \mathrm{C}$ selama 6 jam. Aspal yang digunakan pada penelitian ini adalah aspal dengan penetrasi 60/70.

Pencampuran aspal, karbosil dan silika dilakukan dengan menggunakan hot plate. Aspal dicairkan, silika dan karbosil dimasukkan hingga tercampur rata dan sampel menjadi paduan aspal karbosil silika yang homogen. Selanjutnya dilakukan pemanasan sampel selama 4 jam pada suhu $100{ }^{\circ} \mathrm{C}$. Paduan aspal karbosil digerus dan disaring menggunakan kertas saring ukuran 200 mesh. Setelah itu serbuk paduan aspal karbosil dibentuk menjadi pelet menggunakan alat hydrolic press.

Karakterisasi X-Ray Diffraction (XRD) dilakukan di Laboratorium Material Universitas Andalas, karakterisasi Differential Thermal AnalysisThermogravimetric Analysis (DTA/TGA) dilakukan di Laboratorium Terpadu Universitas Lampung, uji kuat tekan dilakukan di Laboratorium Teknik Mesin Universitas Lampung dan uji pengukuran ketebalan dilakukan di Laboratorium Fisika Material Universitas Lampung. 


\section{HASIL DAN PEMBAHASAN}

\section{Hasil Karakterisasi XRD}

Karakterisasi XRD dilakukan menggunakan X'Pert PRO PANalytical dengan radiasi $\mathrm{Cu}-\mathrm{K} \alpha$ yang dioperasikan pada $40 \mathrm{kV}$ dan $30 \mathrm{~mA}$ dengan sampel berupa serbuk. Step size yang digunakan adalah 0,0260 pada rentang $2 \theta=5-100^{\circ}$ Hasil XRD sampel komposit aspal karbosil silika dengan perbedaan komposisi dapat dilihat pada Gambar 1(a-f). Pada Gambar 1(a) merupakan difraktogram sampel silika dan karbosil tanpa aspal dan Gambar 1(bf) merupakan difraktogram sampel komposit aspal karbosil silika dengan variasi komposisi yang berbeda-beda. Pada Gambar 1(a) menunjukkan sampel memiliki struktur amorf ditandai dengan adanya pola difraksi yang membentuk punuk atau bukit dan memiliki daerah $2 \theta$ yang lebar, yaitu berada pada rentang $2 \theta$ sebesar $19,20^{\circ}-25,83^{\circ}$ yaitu sebesar $10,6^{\circ}$ diidentifikasi sebagai karbon. Hasil ini didukung dengan penelitian [11] yang menunjukkan bahwa keberadaan silika amorf pada rentang $2 \theta$ antara $18^{\circ}-30^{\circ}$ dengan intensitas tertinggi pada $2 \theta$ sebesar $22^{\circ}$ dan keberadaan karbon amorf didukung hasil penelitian [12] yang menunjukkan bahwa keberadaan karbon amorf pada rentang $2 \theta$ sebesar $10,6^{\circ}$.

Pada Gambar 1(b-f) berdasarkan analisis difraktrogram yang diperoleh bahwa dengan penambahan aspal mengakibatkan intensitas silika amorf semakin rendah dan lebar yaitu silika amorf pada rentang $2 \theta=18,2^{\circ}-25,24^{\circ}$ dan karbon amorf pada $2 \theta=10,06^{\circ}-10,63^{\circ}$.

\section{Hasil Karakterisasi DTA/TGA}

Karakteristik termal sampel dianalisis dengan alat DTA/TGA (Exstar TG/DTA 7300). Pengujian dilakukan dari keadaan suhu $30-600{ }^{\circ} \mathrm{C}$ dengan laju kenaikan suhu $5{ }^{0} \mathrm{C} /$ menit. Hasil analisis TGA sampel komposit aspal karbosil silika dengan perbandingan komposisi dapat dilihat pada Gambar 2(a-f). Pada Gambar 2(a-f) memperlihatkan adanya tiga daerah kehilangan massa. Pada daerah I penyusutan

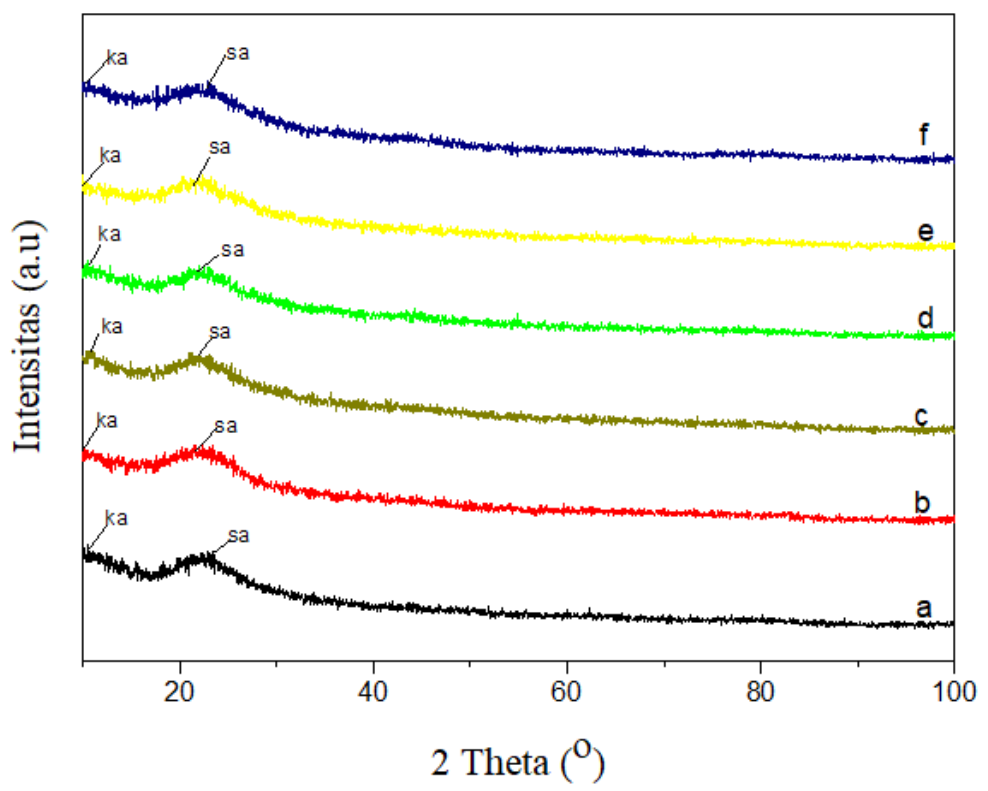

Gambar 1. Difaktogram Sampel Aspal Karbosil Silika (a) Sampel AKS1 perbandingan 0:50:50; (b) Sampel AKS2 perbandingan 15:42,5:42,5; (c) Sampel AKS3 perbandingan 20:40:40; (d) Sampel AKS4 25:37,5:37,5; (e) Sampel AKS5 perbandingan 30:35:35; (f) Sampel AKS6 perbandingan $35: 32,5: 32,5$ 
massa yang sangat kecil terjadi pada kisaran suhu $50-300{ }^{\circ} \mathrm{C}$ yaitu sebesar 7,64, $5,36 \% ; 6,37 \% ; 5,96 \% ; 5,47 \%$ dan $4,92 \%$ untuk masing-masing sampel. Pada daerah I terjadi penyusutan massa yang disebabkan karena terjadinya proses evaporasi atau penguapan air akibat adanya perlakuan panas pada sampel. Hal ini sesuai dengan penelitian yang dilakukan [13] bahwa pada suhu antara 50-300 ${ }^{\circ} \mathrm{C}$ terjadi penyusutan massa disebabkan karena penguapan air yang menunjukkan sampel telah kering. Pada daerah II dengan rentang suhu 300$450{ }^{\circ} \mathrm{C}$ mengindikasikan adanya proses penguapan lebih lanjut senyawa volatil dan dekomposisi asphaltene. Penyusutan massa yang terjadi yaitu sebanyak 13,29\%, $13,97 \%, 17,93 \%, 23,14 \%, 23,52 \%$, dan $25,10 \%$. Pada daerah III dengan rentang suhu $450-650{ }^{\circ} \mathrm{C}$ mengindikasikan adanya proses dekomposisi dari karbosil, silika dan asphalthene. Pada daerah III terjadi penyusutan massa tertinggi yaitu sebanyak $33,37 \%, 31,5 \%, 40,3 \%, 28,5 \%, 43,5 \%$, dan $43,1 \%$ untuk masing-masing sampel. Penyusutan massa secara drastis mengindikasikan adanya proses penguapan senyawa volatil atau proses dekomposisi dari karbosil, silika dan asphalthene. Hal ini sesuai dengan hasil analisis FTIR yang dilakukan [14] yang menunjukan bahwa gugus fungsi $\mathrm{O}-\mathrm{H}$ yang terbentuk mengalami vibrasi regangan yang kemudian membentuk gugus fungsi baru yaitu $\mathrm{Si}-\mathrm{O}-\mathrm{Si}$ serta gugus fungsi $\mathrm{C}-\mathrm{H}$ yang mengalami vibrasi regangan karbonil.

Hasil analisis DTA dapat dilihat pada Gambar 3(a-f). Pada rentang suhu 50-300 ${ }^{\circ} \mathrm{C}$ terdapat kehadiran lembah endotermik yang mengindikasikan terjadinya proses dehidrasi air dan senyawa volatil pada sampel. Hasil ini didukung oleh hasil analisis TGA yang menunjukkan bahwa pada suhu antara 50-300 ${ }^{\circ} \mathrm{C}$ terjadi proses evaporasi yang mengakibatkan penyusutan massa. Pada rentang suhu 300-450 ${ }^{\circ} \mathrm{C}$ terdapat kehadiran puncak eksotermik yang mengindikasikan terjadinya dekomposisi aspal. Hasil ini didukung oleh penelitian dengan hasil FTIR yang menunjukkan kehadiran gugus fungsi $\mathrm{C}=\mathrm{O}$ dan $\mathrm{C}-\mathrm{H}$. Hal ini diakibatkan oleh dekomposisi dari $\mathrm{O}$ dan $\mathrm{H}$ (air) dari dalam karbon silika dengan karbon dari aspal yang menghasilkan ikatan karbonil dengan gugus fungsi $\mathrm{C}=\mathrm{O}$ dan ikatan

$\mathrm{C}-\mathrm{H}$ [15].

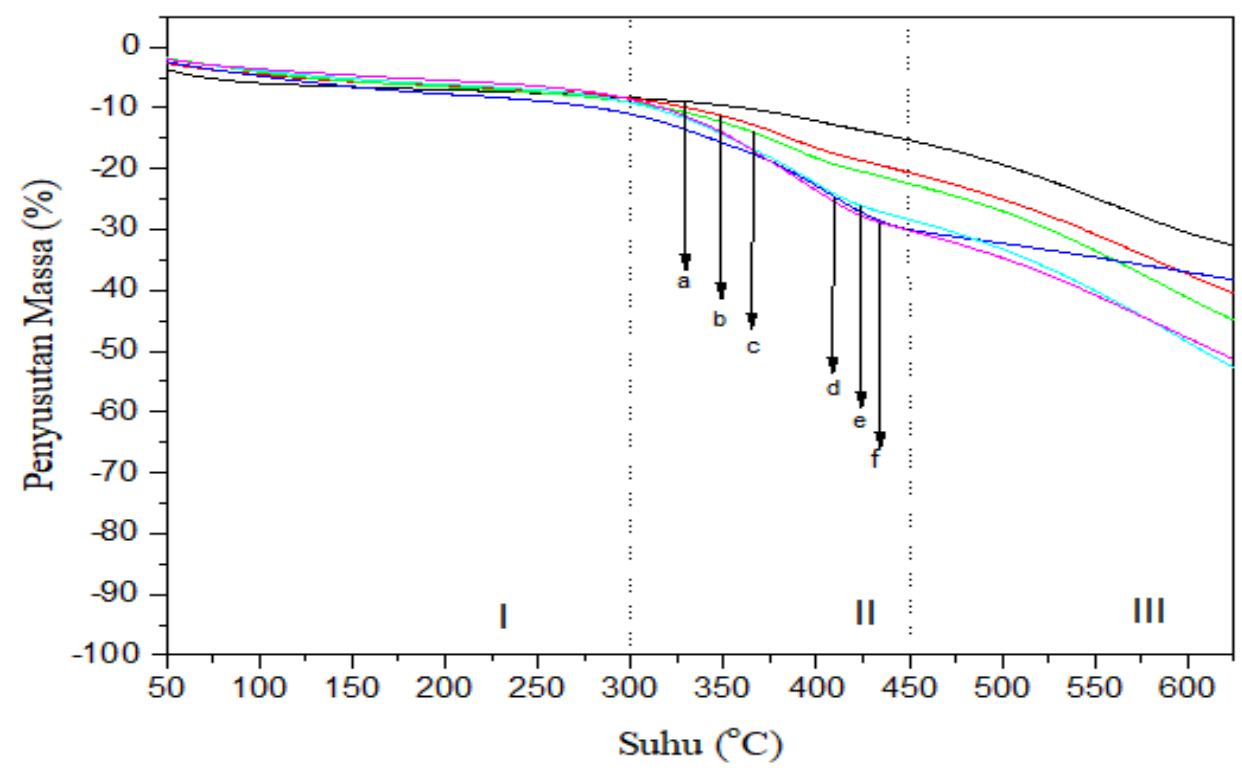

Gambar 2. Hasil uji TGA pada sampel (a) $\mathrm{AKS}_{1}$, (b) $\mathrm{AKS}_{2}$, c) $\mathrm{AKS}_{3}$, (d) $\mathrm{AKS}_{4}$, (e) $\mathrm{AKS}_{5}$, (f) $\mathrm{AKS}_{6}$ 


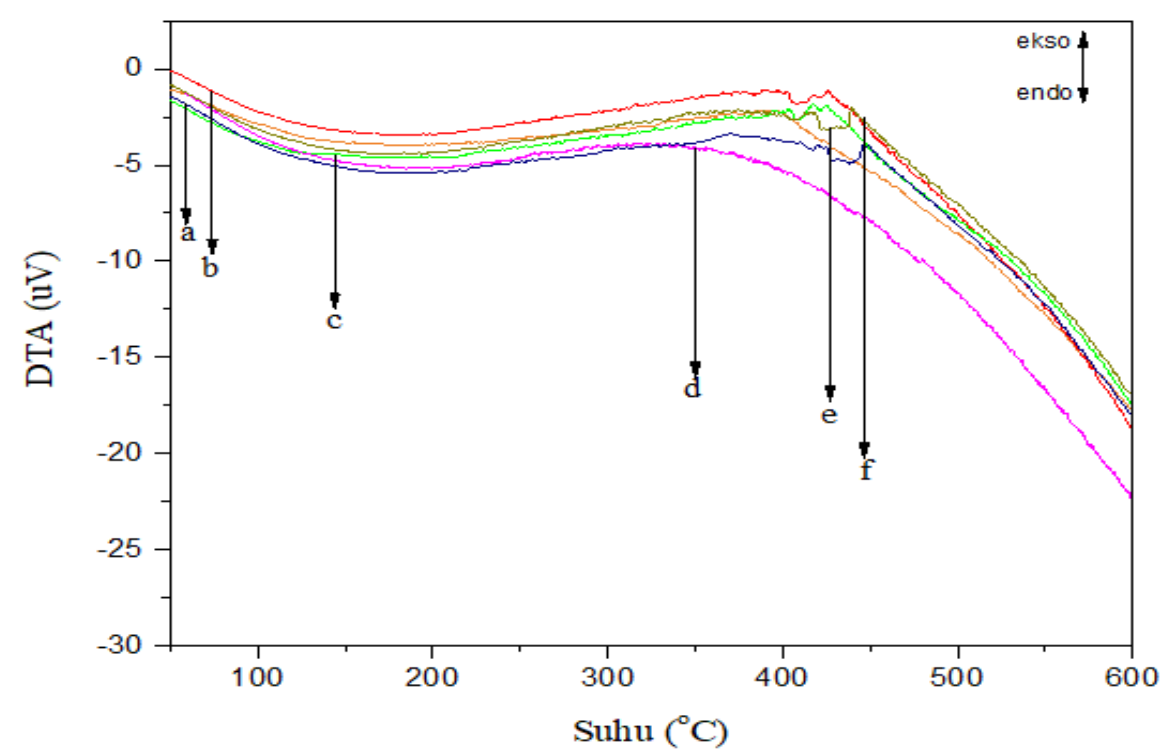

Gambar 3. Hasil uji DTA pada sampel (a) $\mathrm{AKS}_{1}$, (b) $\mathrm{AKS}_{2}$, c) $\mathrm{AKS}_{3}$, (d) $\mathrm{AKS}_{4}$, (e) $\mathrm{AKS}_{5}$, (f) $\mathrm{AKS}_{6}$.

\section{Hasil Kuat Tekan}

Uji kuat tekan dilakukan dengan menggunakan alat Servo Hydraulic Machine. Sampel yang berbentuk pelet dengan diameter $2 \mathrm{~cm}$ diletakkan pada holder Servo Hydraulic Machine dan mensejajarkan sampel dengan diberi beban tekanan $0,15 \mathrm{MPa} /$ detik sampai dengan 0,34 $\mathrm{MPa} /$ detik hingga sampel hancur dan mencatat beban maksimum yang dapat diterima sampel. Hasil kuat tekan ditunjukkan pada Gambar $\mathbf{4}$ bahwa nilai kekuatan tekan semakin menurun dengan bertambahnya jumlah komposisi aspal. Nilai kuat tekan yang dihasilkan yaitu 23,205 MPa, 18,089 MPa, 12,598 Mpa, 9,513 Mpa, 7,778 Mpa dan 7,585 Mpa. Penurunan yang terjadi diindikasikan akibat aspal sudah tidak mampu mengikat silika secara keseluruhan dan kandungan karbon pada aspal yang tinggi membuat jumlah ikatan antar karbon semakin banyak sehingga membuat sampel semakin mudah rapuh.

\section{Hasil Perubahan Ketebalan}

Pengujian perubahan ketebalan menggunakan sampel berbentuk pelet dan dilakukan berdasarkan pada SNI 03-21052006. Adapun proses yang dilakukan yaitu mengukur ketebalan awal sampel $\left(\mathrm{d}_{0}\right)$ menggunakan mikrometer sekrup. Beaker glass diisi dengan akuades $35 \mathrm{ml}$ kemudian sampel dimasukkan ke beaker glass tersebut, lalu didiamkan selama 24 jam untuk mendapatkan nilai ketebalan akhir $\mathrm{d}_{1}$. Nilai perubahan ketebalan dihitung dengan Persamaan 1.

$$
\text { P. Ketebalan }(\%)=\left(\frac{d_{1}-d_{0}}{d_{0}}\right) \times 100 \%
$$

Hasil grafik perubahan ketebalan disajikan pada Gambar 5 menunjukkan bahwa pengurangan jumlah karbosil dan silika menunjukkan pengukuran ketebalan mengalami penurunan. Hal ini didukung dengan penelitian [14] yaitu pengukuran ketebalan sampel dipengaruhi oleh jumlah silika pada komposisi sampel. Nilai hasil pengukuran ketebalan yaitu 37,98 \%, 3,38 $\%, 1,69 \%, 1,24 \%, 0,85 \%$ dan $0,33 \%$. Penurunan ini disebabkan karena karena pori-pori silika tertutupi oleh aspal yang mengakibatkan sampel semakin sedikit menyerap air. 


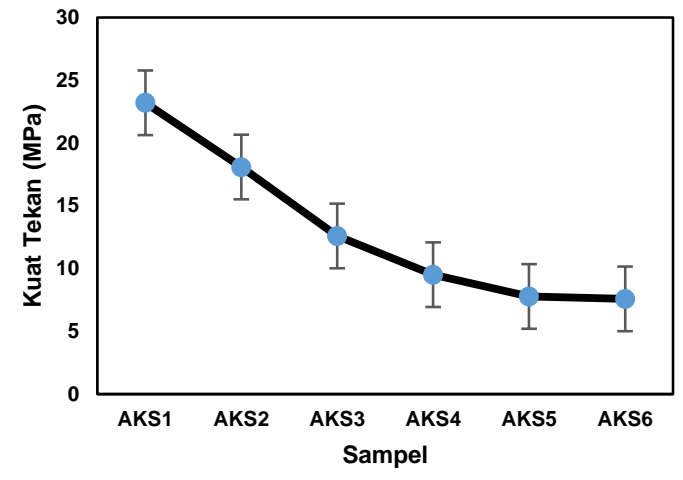

Gambar 4. Grafik Kuat Tekan

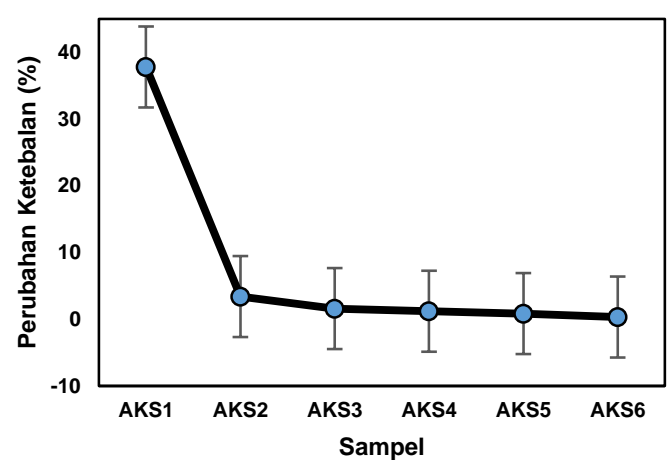

Gambar 5. Perubahan Ketebalan

\section{KESIMPULAN}

Hasil analisis XRD menunjukkan pada setiap sampel fasa yang terbentuk adalah fasa amorf. Hasil DTA/TGA menunjukkan terjadinya proses perubahan energi bahwa komposit aspal silika karbosil memiliki stabilitas yang baik pada suhu tinggi. Selain itu, hasil uji kuat tekan dan perubahan ketebalan pada sampel dengan semakin bertambahnya komposisi aspal maka nilai kuat tekan dan perubahan ketebalan semakin menurun. Sehingga dapat disimpulkan bahwa komposisi paduan yang baik dengan perbandingan massa yaitu pada perbandingan 15:42,5:42,5.

\section{UCAPAN TERIMA KASIH}

Penulis mengucapkan terima kasih kepada dosen pembimbing penelitian, kepala laboratorium fisika material FMIPA
Universitas Lampung dan kepada tim yang terlibat dalam penelitian dan pembuatan jurnal ini.

\section{DAFTAR PUSTAKA}

[1] J. R. Robert Hunter, Andy Self, The Shell Bitumen Handbook, no. September. 2015.

[2] A. P. Exhibit, "v8_1008 - Shell Bitumen Handbook," no. 7. Gambar 5. Grafik Perubahan Ketebalan

[3] M. Enieb and A. Diab, "Characteristics of asphalt binder and mixture containing nanosilica," Int. J. Pavement Res. Technol., vol. 10, no. 2, pp. 148-157, 2017, doi: 10.1016/j.ijprt.2016.11.009.

[4] U. Kalapathy, A. Proctor, and J. Shultz, "A simple method for production of pure silica from rice hull ash," Fuel Energy Abstr., vol. 42, no. 1, p. 45, 2001, doi: 10.1016/s0140-6701(01)80487-2.

[5] K. Fasa and K. S. Sembiring, "Crystoballite Berbasis Silika Sekam Padi Dengan Metode Sintering ( Solid State )," vol. 2, no. 2, pp. 98105.

[6] S. Sembiring, A. Riyanto, R. Situmeang, Z. Sembiring, N. Susanti, and I. Firdaus, "Effect of amorphous rice husk silica addition on the structure of asphalt composite," $J$. Met. Mater. Miner., vol. 30, no. 4, pp. 113-118, 2020, doi: 10.14456/jmmm.2020.59.

[7] L. Xu, T. Long, and Q. Guo, “An easy method to control carbon content in carbosils," Mater. Manuf. Process., vol. 25, no. 7, pp. 654-657, 2010 ,

doi: 
10.1080/10426910903447329.

[8] W. Simanjuntak, S. Sembiring, and K. Sebayang, "Effect of pyrolysis temperatures on composition and electrical conductivity of carbosil prepared from rice husk," Indones. J. Chem., vol. 12, no. 2, pp. 119-125, 2012, doi: 10.22146/ijc.21350.

[9] A. Gierak, F. Czechowski, and R. Leboda, "Improvement of carbonsilica sorbent (carbosil) surface properties upon steam activation at 1073 K," Mater. Chem. Phys., vol. 36, no. 3-4, pp. 264-270, 1994, doi: 10.1016/0254-0584(94)90040-X.

[10] X. Guo, M. Sun, W. Dai, and S. Chen, "Performance characteristics of silane silica modified asphalt," Adv. Mater. Sci. Eng., vol. 2016, 2016, doi: 10.1155/2016/6731232.

[11] T. H. Liou and C. C. Yang, "Synthesis and surface characteristics of nanosilica produced from alkali-extracted rice husk ash," Mater. Sci. Eng. B SolidState Mater. Adv. Technol., vol. 176, no. 7, pp. 521-529, 2011, doi: 10.1016/j.mseb.2011.01.007.

[12] D. Pantea, H. Darmstadt, S. Kaliaguine, L. Sümmchen, and C. Roy, "Electrical conductivity of thermal carbon blacks: Influence of surface chemistry," Carbon N. Y., vol. 39, no. 8, pp. 1147-1158, 2001, doi: $10.1016 / \mathrm{S} 0008-6223(00) 00239$ 6.

[13] X. W. Cheng et al., "A new approach to improve mechanical properties and durability of low-density oil well cement composite reinforced by cellulose fibres in microstructural scale," Constr. Build. Mater., vol.
177, pp. 499-510, 2018, doi: 10.1016/j.conbuildmat.2018.05.134.

[14] S. Sembiring, "Structural Characterisation of Asphalt-Rice Husk Silica Composites," Ceram. Silikaty, vol. 65, no. 3, pp. 1-9, 2021, doi: 10.13168/cs.2021.0021.

[15] S. Sembiring, R. Situmeang, and Z. Sembiring, "Synthesis and characterization of asphalt composite precursors using amorphous rice husk silica," Ceramica, vol. 65, no. 374, pp. 194-199, 2019, doi: 10.1590/0366-69132019653742497. 
Devi Yulianti : Karakteristik Struktur dan Termal Komposit Aspal Karbosil Silika Sekam Padi 